\title{
Myeloid related proteins 8 and 14 (mrp 8/14) - potential biomarkers of disease activity of arthritis in children with trisomy 21
}

\author{
Charlene Foley ${ }^{*}$ Emma MacDermott, Orla Killeen \\ From 21st European Pediatric Rheumatology (PReS) Congress \\ Belgrade, Serbia. 17-21 September 2014
}

\section{Introduction}

JIA is an umbrella term used to describe a heterogeneous group of diseases. To date no specific markers exist in clinical practice to predict disease activity \& outcome. MRP 8/14 are calcium-binding proteins secreted by infiltrating phagocytes in synovial inflammation. Studies have shown that serum $(\mathrm{Se})$ concentrations correlate sensitively \& specifically with synovial inflammation in JIA. It is believed that they are predictive biomarkers that can identify subclinical disease activity, patients at risk of relapse during times of clinically inactive disease, and patients more likely to respond to Rx with MTX. To date there have been no studies looking specifically at their use in DA. Research Q(s) - 1. Are MRP8/14 accurate markers of inflammation in DA? 2. Do MRP 8/14 levels in Se correlate to Synovial Fluid (SF)?

\section{Objectives}

Evaluate the use of CRP, ESR \& MRP 8/14 as biomarkers of disease activity in DA \& JIA.

\section{Methods}

Between May 2013-May 2014, new cases of JIA \& DA attending the NCPR had blood drawn to measure their CRP, ESR \& MRP 8/14 levels at dx. Corresponding AJC was documented. Paired SF samples were taken for analysis from children requiring steroid JIs as $\mathrm{Rx}$ for their arthritis. Se \& SF MRP 8/14 were determined by sandwich ELISA.

\section{Results}

32 children (20 JIA, 12 DA) had Se samples taken for CRP, ESR \& MRP 8/14 levels at diagnosis. 14 of these children had paired SF samples taken. Table 1 highlights accuracy of each measurement as a marker of disease activity. In DA, a significant correlation was detected between AJC \& both ESR \& MRP 8/14 (SF). Combining results for the DA \& JIA cohort, a significant positive correlation was noted between paired samples of MRP $8 / 14$ in Se \& SF.

\section{Conclusion}

MRI with contrast remains the gold standard for $\mathrm{dx}$ of synovitis. In reality, clinical assessment is the major diagnostic tool. DA is a more challenging condition than JIA, in light of confounding illness \& the oftenassociated non-verbal state. In DA a simple biomarker of disease would be invaluable. We have shown that CRP is a poor marker of disease activity in JIA \& DA, so the need for a more specific biomarker is evident. Our preliminary results suggest that children with DA have elevated SF levels of MRP 8/14 that correlate to disease activity. SF MRP 8/14 measurements are significantly higher than their paired Se samples, however our results show significant positive correlation between the two. This suggests that Se MRP 8/14 levels are potentially accurate markers of SF levels. MRP 8/14 may be a useful biomarker in DA, aiding timely $\mathrm{dx} \&$ instigation of appropriate $\mathrm{Rx}$, helping to improve clinical outcomes for this group. 
Table 1

\begin{tabular}{|c|c|c|c|c|c|}
\hline \multicolumn{6}{|c|}{ ( $n=32$ serum, $n=14$ synovial fluid) } \\
\hline Dx & Statistical test & Variable 1 & Variable 2 & Correlation & $\mathrm{p}$ value \\
\hline \multirow[t]{4}{*}{ DA } & Correlation & Active Joint & ESR & Positive & $\mathrm{p}<0.05$ \\
\hline & & Count & MRP 8/14 SF & Positive & $\mathrm{p}<0.05$ \\
\hline & & $(\mathrm{AJC})$ & CRP & No Correlation & ns \\
\hline & & MRP 8/14 SF & ESR & Positive & $\mathrm{p}<0.01$ \\
\hline JIA/DA & Correlation & MRP 8/14 SF & MRP $8 / 14$ serum & Positive & $\mathrm{p}<0.05$ \\
\hline Dx & Statistical test & Variable 1 & Variable 2 & Outcome & $\mathrm{p}$ value \\
\hline JIA/DA & Paired $t$ test & MRP 8/14 SF & MRP $8 / 14 \mathrm{Se}$ & SF MRP8/14 signif.higher than matched SeMRP8/14 & $\mathrm{p}<0.01$ \\
\hline
\end{tabular}

\section{Disclosure of interest}

None declared

Published: 17 September 2014

doi:10.1186/1546-0096-12-S1-P182

Cite this article as: Foley et al:: Myeloid related proteins 8 and 14

(mrp 8/14) - potential biomarkers of disease activity of arthritis in

children with trisomy 21. Pediatric Rheumatology 2014 12(Suppl 1):P182.

Submit your next manuscript to BioMed Central and take full advantage of:

- Convenient online submission

- Thorough peer review

- No space constraints or color figure charges

- Immediate publication on acceptance

- Inclusion in PubMed, CAS, Scopus and Google Scholar

- Research which is freely available for redistribution

Submit your manuscript at www.biomedcentral.com/submit 